\title{
Gardening Intervention for Physical and Psychological Health Benefits in Elderly Women at Community Centers
}

\author{
Sin-Ae Park ${ }^{1}$, A-Young Lee ${ }^{2}$, Ki-Cheol Son ${ }^{1,2}$, Wang-Lok Lee ${ }^{3,5}$, \\ and Dae-Sik Kim ${ }^{4,5,6}$
}

AdDitional INDEX wORDs. geriatric depression scale, hand function ability, horticultural therapy, physical function ability, sociality

Summary. The present study aimed to assess the physical and psychological health benefits of a 15-session gardening intervention in elderly women and to investigate satisfaction of the gardening intervention. Fifty elderly women (age $>70$ years) at two senior community centers located in Seoul, South Korea, were selected to participate in this study. Twenty-four elderly women at senior community center "A" participated in a twice-weekly gardening intervention $(\approx \mathbf{5 0}$ minutes per session) during the period Sept. to Nov. 2015; 26 elderly women at senior community center " $B$ " comprised a control group. At the completion of the 15 session gardening intervention, physical health parameters such as body composition, physical functional ability, and hand function ability were assessed in both groups. Additionally, psychological health conditions, such as cognitive ability, depression, and sociality, were assessed. The elderly women also answered a questionnaire to assess the amount of physical activity experienced during daily life. Elderly women in the gardening intervention group exhibited significantly improved muscle mass, aerobic endurance, hand dexterity, cognitive ability, and decreased waist circumference $(P<0.05)$. In contrast, significantly decreased muscle mass and agility and increased depression were observed in the control group $(P<$ 0.05 ). Moreover, elderly women in the gardening intervention group reported a significantly higher amount of daily physical activity compared with those in the control group $(P<0.05)$. Additionally, $95.8 \%$ of elderly women in the gardening intervention group reported of being very satisfied with the gardening intervention. In conclusion, the gardening intervention maintained and improved the physical and psychological health of elderly women at a senior community center, whereas elderly women in the control group experienced age-related reduced physical and psychological health conditions. More studies are needed to evaluate the effects of a gardening intervention in a larger population of elderly women; in addition, a longer intervention period would provide a better measure of health in elderly women.

\section{A}

ging is characterized by a decrease in complex functional abilities related to the physical, psychological, cognitive, and social aspects of life (Brandtstädter and Greve, 1994). In addition, muscle mass, muscle strength, and physical fitness level decline with advancing age (Rikli and

This paper was supported by the SMART Research Professor Program of Konkuk University. This work was supported by research fund of Chungnam $\mathrm{Na}$ tional University.

${ }^{1}$ Department of Environmental Health Science, Konkuk University, Seoul 05029, South Korea

${ }^{2}$ Graduate School of Environmental Science, Konkuk University, Seoul 05029, South Korea

${ }^{3}$ Department of Sport Science, Chungnam National University, Daejeon 34134, South Korea

${ }^{4}$ Department of Agricultural and Rural Engineering, Chungnam National University, Daejeon 34134, South Korea

${ }^{5}$ These authors contributed equally to this work

${ }^{6}$ Corresponding author. E-mail: drkds19@cnu.ac.kr.
Jones, 1999a). Late-life depression is a crucial public health problem because it can increase the risks of morbidity and suicide and decrease an individual's physical, cognitive, and social functional abilities (Fiske et al., 2009). Furthermore, elderly people experience age-related losses of cognitive abilities, such as memory, attention, and learning (Driscoll et al., 2003). The effects of social changes may also affect an elderly individual's social participation ability or social relationships (Brandtstädter and Greve, 1994).

Meanwhile, regular physical activity confers health benefits, including the prevention or improvement of chronic health problems related to the physical, psychological, cognitive, and social aspects of life (DiPietro, 2001; Weir, 2010). Despite the importance of regular physical activity, however, most elderly individuals spend $80 \%$ of their daily time in sedentary activities (de Rezende et al., 2014).

Gardening is a popular leisure time physical activity among elderly individuals (Ashe et al., 2009; Rowinski et al., 2015), especially in the United States, Canada, and some European countries (Ashe et al., 2009; Rowinski et al., 2015). In addition, urban agriculture is also increasing in popularity (Mougeot, 2006) and has been implemented in the United States, Canada, European countries, and Asian countries (Lovell, 2010; McClintock, 2010; van Leeuwen et al., 2010). Given the popularity of gardening, the present study aimed to assess the physical and psychological health benefits of gardening as a physical activity intervention for maintaining or improving the health conditions of elderly women at a community senior center and to investigate satisfaction of the gardening intervention.

\section{Materials and methods}

RECRUITMENT AND EXPERIMENTAL DESIGN. To recruit elderly women at senior community centers to this study, a flyer containing descriptions of the study purpose, gardening intervention, and health measurements was distributed at $\approx 40$ senior community centers in Seoul, South Korea. Two senior community centers located in the same community, Gangnam-gu, were selected for the study and most of the elderly women $(\approx 98 \%$ of the elderly women in each center; $24 / 25$ and 26 / 27 , respectively) decided to participate in this study. Therefore, a total of

\begin{tabular}{llll}
\hline $\begin{array}{l}\text { Units } \\
\text { To convert U.S. to SI, } \\
\text { multiply by }\end{array}$ & U.S. unit & SI unit & $\begin{array}{l}\text { To convert SI to U.S., } \\
\text { multiply by }\end{array}$ \\
\hline 0.3048 & $\mathrm{ft}$ & $\mathrm{m}$ & 3.2808 \\
0.0929 & $\mathrm{ft}^{2}$ & $\mathrm{~m}^{2}$ & 10.7639 \\
2.54 & inch $(\mathrm{es})$ & $\mathrm{cm}$ & 0.3937 \\
0.4536 & $\mathrm{lb}$ & $\mathrm{kg}$ & 2.2046 \\
4.8824 & $\mathrm{lb} / \mathrm{ft}^{2}$ & $\mathrm{~kg} \cdot \mathrm{m}^{-2}$ & 0.2048 \\
28.3495 & $\mathrm{Oz}$ & $\mathrm{g}$ & 0.0353 \\
$\left({ }^{\circ} \mathrm{F}-32\right) \div 1.8$ & ${ }^{\circ} \mathrm{F}$ & ${ }^{\circ} \mathrm{C}$ & $\left({ }^{\circ} \mathrm{C} \times 1.8\right)+32$
\end{tabular}


50 Korean elderly women at these centers submitted consent forms to participate.

This study featured a quasiexperimental design with a nonequivalent control group. The 24 elderly women at senior community center "A" participated in the 15-session gardening intervention. An additional 26 elderly women at senior community center "B" did not participate in any gardening intervention during the study period and were considered the control group. Both groups were subjected to health assessments before and after the gardening intervention. Each participant received an incentive (equivalent to $\$ 20$ ) at the completion of the study. This study was approved by the institutional review board (7001355201507-HR-067).

G A R D E N I N G A C T I V I T Y INTERVENTION. The 15-session gardening intervention was conducted during the period from Sept. to Nov. 2015 for fall gardening. This intervention was managed primarily by a horticultural therapist with three assistant horticultural therapists, all of whom were certified by the Korean Horticultural Therapy and Wellbeing Association. The intervention involved twice-weekly sessions for an average duration of $50 \mathrm{~min}$ per session. A garden plot $(8.0 \times 5.1 \mathrm{~m})$ had been installed in the front yard of senior community center " $A$ " for this project, and the intervention comprised making plant beds via tasks such as garden design and planning, making furrows in the plots, making name tags for each garden plot, planting transplants, garden maintenance (e.g., fertilizing, weeding, watering, harvesting), and other activities such as flower arrangement and garden parties involving harvested products (Table 1). The participants were allowed to take short breaks during the gardening intervention as needed to address their physical burdens.

The Centers for Disease Control and Prevention and the American College of Sports Medicine recommend that adults participate in at least $150 \mathrm{~min}$ of moderate-intensity physical activity per week to improve or maintain health (Nelson et al., 2007; Pate et al., 1995). Moreover, participation in lowintensity physical activity has been suggested to improve the daily living abilities of elderly individuals by increasing balance, flexibility, and muscle strength (Brown et al., 2000; Buman et al., 2010). Therefore, the gardening activities that comprised this intervention were selected to represent low- to moderate-intensity physical activities that would yield similar health improvements or maintenance. Previously reported metabolic cost data were used to select these gardening activities (Park et al., 2011, 2012, 2014a). Specifically, studies conducted by Park et al. (2011, 2012, 2014a) provided exercise intensity data of various gardening activities performed by older adults.

The following seasonal plants were grown in the garden plot or used for indoor horticultural activities as part of the gardening intervention: chives (Allium ascalonicum), chinese cabbage (Brassica rapa var. pekinensis), radish (Raphanus sativus), lettuce (Lactuca sativa), crown daisy (Chrysanthemum coronarium var. spatiosum), kohlrabi (Brassica oleracea var. gongylodes), beet (Beta vulgaris), onion (Allium cepa), spinach (Spinacia oleracea), crown of thorns (Euphorbia milii var. splendens), chrysanthemum (Chrysanthemum morifolium), zinnia (Zinnia elegans), rose (Rosa bybrida), golden pothos (Epipremnum aureum), and peperomia (Peperomia clusiifolia). The average weather conditions during the study period included a temperature of (mean \pm SD ) $17.5 \pm 4.4{ }^{\circ} \mathrm{C}$ and relative humidity of $56.9 \% \pm 10.0 \%$ (Korean Meteorological Administration, 2015).

Health assessments. Researchers prepared rooms at both senior community centers for the health assessments conducted before and after the 15-session gardening intervention. Physical health conditions, including body composition, physical functional ability, and hand function ability, and psychological health conditions, including cognitive ability, depression, and sociality, were assessed.

To measure factors related to body composition such as body weight (kilograms), fat mass (grams), lean mass (grams), and fat (percent), participants were evaluated with a body fat analyzer (ioi 353; Jawon Medical, Gyeongsan, South Korea) after removing shoes. Height was measured using an anthropometer (Ok7979; Samhwa, Seoul, South Korea). Weight and height data were used to calculate the body mass index as the body weight (kilograms) divided by the height squared (square meters). A measuring tape (Pitting measure KMC-220; Komelon, Gyeongsan,
South Korea) was used to measure the waist circumference at the area between the bottom of the ribs and the upper crista iliaca (World Health Organization, 2011) and the hip circumference at the most protruding part of the hip. The waist-hip ratio was calculated as the waist circumference (centimeters) divided by the hip circumference (centimeters).

The Senior Fitness Test was used to assess physical functional ability (Rikli and Jones, 2013). This test was developed as a tool for evaluating the functional fitness performance of older adults (Rikli and Jones, 2001) and measures physiologic parameters using functional movement tasks, such as standing, bending, lifting, reaching, and walking. This test meets scientific standards for validity and reliability (Rikli and Jones, 1999b), and ageand gender-based norms determined from more than 7000 older adults in 21 states of the United States have been published for each test item.

The Senior Fitness Test comprises six assessment items (Rikli and Jones, 2013): a chair stand test, arm curl test, chair sit-and-reach test, back scratch test, 2 -min step test, and 8 -ft up-and-go test. Before starting each test, the researchers provided an oral explanation and demonstration of how to perform the test to the subjects, who were then allowed to practice the test motions. For the chair stand test, which assesses lower body strength, each subject completed one test trial during which the total number of stands within $30 \mathrm{~s}$ was counted. For the arm curl test, which assesses upper body strength, each subject completed one test trial during which the total number of hand weight curls through the full range of motion within $30 \mathrm{~s}$ was counted. The 2 -min step test assesses aerobic endurance; each subject completed one trial and the score was calculated as the total number of steps within $2 \mathrm{~min}$. The 8 -ft up-and-go test assessed agility and dynamic balance; each subject completed two test trials and the score was the shortest time to rise from a seated position, walk 8 - $\mathrm{ft}$, turn, and return to the seated position. The chair sit-and-reach test assessed lower body flexibility; each subject completed two repetitions of this test, and the score was the best distance (centimeters) achieved between the extended fingers and the tip of the toe. The back scratch test assessed upper body flexibility; each subject completed two test 
Table 1. A 15-session gardening intervention for the improvement of physical and psychological health conditions of elderly women.

\begin{tabular}{|c|c|c|c|c|}
\hline Session & Gardening activity & Plant used & Gardening tool & Estimated METs ${ }^{\mathrm{z}}$ \\
\hline 1 & $\begin{array}{l}\text { Design garden and making } \\
\text { garden plots }\end{array}$ & - & $\begin{array}{l}\text { Drainpipe }[50 \times 50 \mathrm{~cm} \\
\quad(19.7 \text { inches })] \\
\text { nonwoven fabric for } \\
\text { farming }\end{array}$ & 3.4 \\
\hline 2 & Planting transplants & Chives & $\begin{array}{l}\text { Peatmoss, perlite, shovel, } \\
\text { rake }\end{array}$ & 3.7 \\
\hline 4 & Making garden signs & - & Wooden boards, paint, saw & 2.8 \\
\hline 5 & Maintaining garden & Golden pothos & $\begin{array}{l}\text { Hydroball, pot, bucket, } \\
\text { watering can, hose }\end{array}$ & 2.3 \\
\hline 6 & Fertilizing & - & fertilizer, trowel, hoe & 4.0 \\
\hline 7 & Making flower garden beds & $\begin{array}{l}\text { Crown of thorns, } \\
\text { chrysanthemum, } \\
\text { zinnia }\end{array}$ & $\begin{array}{l}\text { Gardening box, trowel, } \\
\text { watering can, peatmoss, } \\
\text { perlite }\end{array}$ & 2.5 \\
\hline 9 & Making organic fertilizers & - & $\begin{array}{l}\text { Egg, vinegar, plastic } \\
\text { bottle, watering can }\end{array}$ & 2.8 \\
\hline 10 & Maintaining garden & - & $\begin{array}{l}\text { Fertilizer, straw for } \\
\text { mulching }\end{array}$ & 2.7 \\
\hline 11 & Planting plants & Peperomia, rose & $\begin{array}{l}\text { Peatmoss, perlite, pot, } \\
\text { watering can, name tag }\end{array}$ & 2.4 \\
\hline 12 & Maintaining garden & - & $\begin{array}{l}\text { Spray, organic fertilizers, } \\
\text { straw for mulching }\end{array}$ & 3.3 \\
\hline 13 & Flower arrangement & Chrysanthemum & $\begin{array}{l}\text { Vase, floral form, } \\
\text { wrapping, ribbon }\end{array}$ & 2.3 \\
\hline
\end{tabular}

${ }^{2}$ Estimated metabolic equivalents (METs) based on the previous studies for measuring exercise intensities of gardening tasks (Park et al., 2011, 2012, 2014a) and a study for compendium of physical activities (Ainsworth et al., 2000). Intensities below 3.0 METs indicate a low-intensity physical activity and above 3.0 to 6.0 METs presents moderateintensity physical activities.

repetitions and the score was the best distance (centimeters) achieved between the extended middle fingers.

Grip strength, pinch force, and hand dexterity were measured using a digital grip dynamometer (KS-301; Lavisen, Namyangju-si, South Korea), Jamar hydraulic pinch gauge (749805; Sammons Preston, Ashburn, VA), and grooved pegboard (32025; Lafayette, Lafayette, CA), respectively. Triplicate grip strength and pinch force measurements of the dominant hand were performed, whereas duplicate hand dexterity measurements were performed. Hand dexterity (fine motor skill) is defined as the ability to coordinate small muscle movements that usually involve the synchronization of hands and fingers with the eyes (Barnsley and Rabinovich, 1970; Fleishman, 1972).

Cognitive function ability was measured using the Korean Mini Mental
State Examination [K-MMSE (Kang et al., 1997)]. The K-MMSE comprises the following subscales: disorientation of time (five scores), disorientation of place (five scores), memory (three scores), attention and calculation (five scores), memory recall (three scores), language (eight scores), and composition of time and space (one score). Total scores range from 0 to 30 . A score of $\geq 24$ indicates normal ability, a score of 18-23 indicates mild cognitive impairment, and a score of $\geq 17$ indicates severe cognitive impairment. The test-retest reliability of this instrument is 0.86 (Kang et al., 1997).

Depression was assessed using the Korean Version of the Short Form of Geriatric Depression Scale (Ki, 1996; Yesavage and Sheikh, 1986). This scale includes 15 questions related to depression in the elderly. A higher score indicates stronger symptoms of depression; specifically, a score of less than 5 indicates a normal state, a score of 6-9 indicates moderate depression, and a score of more than 10 indicates severe depression (Ki, 1996). Cronbach's $\alpha$ of this instrument is $0.88(\mathrm{Ki}, 1996)$.

To evaluate the social behaviors of elderly subjects, a sociality survey developed by Song (2000) and Seok (2005) was used. Twenty-two questions addressed issues related to competence, expandability, and intimacy. Total scores range from 0 to 110 points, with a higher score indicating better social behaviors. Cronbach's $\alpha$ of this survey is 0.80 (Bae, 2009).

The International Physical Activity Questionnaire-Short Form (IPAQ Research Committee, 2005 ) was used to determine the duration and exercise intensity of daily physical activities during the previous $7 \mathrm{~d}$. Self-reported physical activities were measured in units 
of the metabolic equivalent (MET) of a task. Specifically, a MET-min is computed by multiplying the MET score by the minutes performed.

At the beginning of the study, demographic information, such as age, education level, marital status, and monthly income, was obtained via questionnaire from subjects in both groups. Additionally, a satisfaction survey regarding the gardening intervention (Park et al., 2015) was modified for this study and completed by participants in the gardening intervention group at the end of the 15-session gardening intervention. This satisfaction survey comprised a total of seven questions, including questions about overall satisfaction with the gardening intervention (e.g., what is your overall satisfaction for the gardening intervention?), the duration per session in the intervention (e.g., were you satisfied with the $50 \mathrm{~min}$ per session?), and frequency in the intervention (e.g., were you satisfied with the frequency of twice per week?). The responses were conducted based on a 5-point Likert-scale (very satisfied, satisfied, moderately satisfied, not satisfied, or very not satisfied). Moreover, a question regarding self-reported benefits of gardening intervention (e.g., what are the benefits of gardening?) was answered subjectively. Questions regarding desire to continue participating in the gardening intervention (e.g., do you wish to continue participating in the gardening intervention?) and the intention of recommending the program to others (e.g., do you recommend the gardening intervention to others?) were answered with a simple yes or no. Question regarding preference for the performed gardening activities (e.g., what was the most preferred activity in the gardening intervention?) asked participants to choose their three most preferred activities.

Data analysis. The Wilcoxon signed-rank test and SPSS software (version 18 for Windows; IBM, Armonk, $\mathrm{NY}$ ) were used to compare the results of pre- and post-intervention tests to evaluate physical, psychological, and cognitive health aspects in the control and gardening intervention groups. Demographic information and satisfaction with the gardening intervention were analyzed using Excel software (Office 2007; Microsoft Corp., Redmond, WA); additional analyses involving the chi-square test were conducted using SPSS software. A probability value $<0.05$ was considered to indicate statistical significance.

\section{Results and discussion}

DEMOGRAPHIC CHARACTERISTICS. The elderly women who participated in the gardening intervention and control groups were aged (mean \pm SD) $79.4 \pm 4.8$ and $84.5 \pm 4.7$ years, respectively, and this difference was significant $[P<0.05$ (Table 2$)]$. The average height of the gardening intervention group was taller than that of the control group (Table 2). No significant differences were observed in other variables [e.g., educational level, marital status, monthly income, and current chronic diseases (Table 2)]. Elderly women in both groups reported a low level of education (elementary school graduation or less) and a low monthly income $[<\$ 1000$ (Table 2)]. The most common chronic diseases in both groups were high blood pressure and diabetes (Table 2).

Additionally, the administration type of the senior centers is similar because the two senior centers are located in the same community. The senior centers provided leisure time activities, such as stretching exercises or yoga, as well as part-time job opportunities. Most elderly attendees at the senior centers participate in sitting activities such as playing card games, which comprise a sedentary lifestyle (Dunstan et al., 2012).

The intervention attendance rate among elderly women in the gardening intervention group was $80 \%$, and regular checkups and sickness were cited as reasons for absence.

Physical health assessments. The elderly women in the gardening intervention exhibited a significant decrease in waist circumference from $88.0 \pm 10.9 \mathrm{~cm}$ (pre-intervention) to

Table 2. Comparisons of demographic information of the subjects in a study for the improvement of physical and psychological health conditions of elderly women through a 15-session gardening intervention by using chi-square and Mann-Whitney $U$ tests. $^{\mathrm{z}}$

\begin{tabular}{|c|c|c|c|}
\hline Variable & $\begin{array}{c}\text { Gardening } \\
(\mathrm{n}=24)\end{array}$ & $\begin{array}{l}\text { Control } \\
(\mathrm{n}=26)\end{array}$ & Significance \\
\hline \multicolumn{4}{|c|}{ Mean (SD) } \\
\hline Age (years) & $79.4(4.8)$ & $84.5(4.7)$ & ** \\
\hline \multicolumn{4}{|c|}{ Percentage $(\mathrm{N})$} \\
\hline \multicolumn{4}{|l|}{ Disease } \\
\hline Hypertension & $82.6(19)$ & $76.0(19)$ & NS \\
\hline Diabetes & $30.4(7)$ & $40.0(10)$ & NS \\
\hline Hyperlipidaemic & $8.7(2)$ & $4.0(1)$ & NS \\
\hline Arthritis & $4.3(1)$ & $20.0(5)$ & NS \\
\hline Lumbar disc & $0.0(0)$ & $12.0(3)$ & NS \\
\hline Osteoporosis & $0.0(0)$ & $12.0(3)$ & NS \\
\hline Angina & $0.0(0)$ & $8.0(2)$ & NS \\
\hline Neuralgia & $4.3(1)$ & $4.0(1)$ & NS \\
\hline Cataract & $0.0(0)$ & $4.0(1)$ & NS \\
\hline Liver cirrhosis & $4.3(1)$ & $0.0(0)$ & NS \\
\hline Hyperthyroidism & $4.3(1)$ & $0.0(0)$ & NS \\
\hline Hip disease & $0.0(0)$ & $4.0(1)$ & NS \\
\hline Parkinson's disease & $0.0(0)$ & $4.0(1)$ & NS \\
\hline Breast cancer & $0.0(0)$ & $4.0(1)$ & NS \\
\hline \multicolumn{4}{|l|}{ Education } \\
\hline Elementary school graduate or less & $91.3(21)$ & $100.0(25)$ & NS \\
\hline Middle school graduate & $8.7(2)$ & $0.0(0)$ & \\
\hline \multicolumn{4}{|l|}{ Marital status } \\
\hline Widowed & $82.6(19)$ & $88.0(22)$ & NS \\
\hline Married & $17.4(4)$ & $12.0(3)$ & \\
\hline \multicolumn{4}{|l|}{ Monthly income } \\
\hline Less than $\$ 850$ & $95.7(22)$ & $96.0(24)$ & NS \\
\hline$\$ 850$ to $\$ 1,700$ & $4.3(1)$ & $0.0(0)$ & \\
\hline$\$ 1,700$ to $\$ 2,550$ & $0.0(0)$ & $4.0(1)$ & \\
\hline
\end{tabular}

${ }^{\mathrm{z}}$ Chi square was used to compare values at $P<0.05$ for disease, education, marital status, monthly income, and Mann-Whitney $U$ test was used to compare means at $P<0.05$ for the age. $\mathrm{NS},{ }^{*}$ Nonsignificant or significant at $P<0.05$, respectively. 
$87.1 \pm 10.6 \mathrm{~cm}$ [post-intervention, $P<0.05$ (Table 3)]. Although there was no standard index value of waist circumference for elderly, the appropriate cutoff point of waist circumference for obesity for Koreans was suggested to be $90 \mathrm{~cm}$ for men and $85 \mathrm{~cm}$ for women (Lee et al., 2007). Meanwhile, there was no significant difference of waist circumference in the control group, but it showed a tendency to slightly increase. In contrast to the reduced waist circumference observed among elderly women in the gardening intervention group, waist circumference has been reported to increase with age (Ford et al., 2003). Lahti-Koski et al. (2007) reported an average 15year increase in waist circumference of $2.7 \mathrm{~cm}$ among male adults and $4.3 \mathrm{~cm}$ among female adults. Both the waist circumference and waist-hip ratio are important indicators of the risks of

Table 3. Wilcoxon test comparisons of body compositions of elderly women before and after a gardening intervention.

\begin{tabular}{|c|c|c|c|}
\hline \multirow[b]{2}{*}{ Variable } & & \multicolumn{2}{|c|}{ Group } \\
\hline & & $\frac{\text { Gardening }}{\text { Mean (SD) }}$ & $\frac{\text { Control }}{\text { Mean (SD) }}$ \\
\hline \multirow[t]{3}{*}{ Height $(\mathrm{cm})^{\mathrm{z}}$} & Pre-test & $149.3(3.6)$ & $147.9(4.4)$ \\
\hline & Post-test & $148.4(3.5)$ & $147.6(4.7)$ \\
\hline & Significance & $\star * *$ & NS \\
\hline \multirow[t]{3}{*}{ Body weight $(\mathrm{kg})^{z, x}$} & Pre-test & $58.6(9.3)$ & $54.1(7.3)$ \\
\hline & Post-test & $58.4(9.5)$ & $53.4(7.3)$ \\
\hline & Significance & NS & $* *$ \\
\hline \multirow[t]{3}{*}{ Lean mass $(\mathrm{kg})^{\mathrm{z}, \mathrm{x}}$} & Pre-test & $32.9(2.4)$ & $31.1(3.2)$ \\
\hline & Post-test & $32.5(2.2)$ & $30.8(4.2)$ \\
\hline & Significance & NS & * \\
\hline \multirow[t]{3}{*}{ Fat $(\mathrm{kg})^{\mathrm{z}, \mathrm{x}}$} & Pre-test & $36.3(4.2)$ & $31.1(3.2)$ \\
\hline & Post-test & $36.2(4.4)$ & $30.8(3.3)$ \\
\hline & Significance & NS & NS \\
\hline \multirow[t]{3}{*}{ Body mass index $\left(\mathrm{kg} \cdot \mathrm{m}^{-2}\right)^{\mathrm{z}, \mathrm{x}}$} & Pre-test & $25.7(4.0)$ & $24.6(3.5)$ \\
\hline & Post-test & $25.7(4.2)$ & $24.5(3.4)$ \\
\hline & Significance & NS & NS \\
\hline \multirow[t]{3}{*}{ Percent fat $(\%)^{x}$} & Pre-test & $36.3(4.2)$ & $36.4(4.1)$ \\
\hline & Post-test & $36.2(4.4)$ & $36.4(4.2)$ \\
\hline & Significance & NS & NS \\
\hline \multirow[t]{3}{*}{ Waist circumference $(\mathrm{cm})^{\mathrm{z}, \mathrm{y}}$} & Pre-test & $88.0(10.9)$ & $84.3(8.4)$ \\
\hline & Post-test & $87.1(10.6)$ & $85.3(8.3)$ \\
\hline & Significance & * & * \\
\hline \multirow[t]{4}{*}{ Hip circumference $(\mathrm{cm})^{\mathrm{z}, \mathrm{y}}$} & Pre-test & $99.5(9.2)$ & $96.0(5.4)$ \\
\hline & Post-test & $98.6(9.3)$ & $96.3(5.8)$ \\
\hline & Significance & NS & NS \\
\hline & Pre-test & $0.88(0.04)$ & $0.88(0.05)$ \\
\hline \multirow[t]{2}{*}{ Waist-hip ratio } & Post-test & $0.88(0.05)$ & $0.88(0.06)$ \\
\hline & Significance & NS & NS \\
\hline
\end{tabular}

${ }^{2} 1 \mathrm{~cm}=0.3937$ inch, $1 \mathrm{~kg}=2.2046 \mathrm{lb}, \mathrm{l} \mathrm{kg} \cdot \mathrm{m}^{-2}=0.2048 \mathrm{lb} / \mathrm{ft}^{2}$

y Measured using a measuring tape (Pitting measure KMC-220; Komelon, Gyeongsan, Korea). Waist circumference is measured at the midpoint between the lower margin of the least palpable rib and the top of the iliac crest. Hip circumference is measured around the widest portion of the buttocks, with the tape parallel to the floor. Waisthip ratio is calculated as waist measurement divided by hip measurement (World Health Organization, 2011).

${ }^{x}$ Measured using a body fat analyzer (ioi 353; Jawon Medical, Gyeongsan, Korea).

Ns, ${ }^{*},{ }^{*},{ }^{* *}$ Nonsignificant or significant at $P<0.05$, respectively.

cardiovascular disease and abdominal obesity (Huxley et al., 2010). Accordphe this study suggests gardening as activity intervention could (entis diseases, such as cardiovascular disease, abdomend and diabetes.

weight, lean mass, fat mass, and body mass index were observed because of the gardening intervention. Elderly men in the control group exhibited $7.3 \mathrm{~kg}$ (post-test, $P<0.05$ ), as well as ean mass from $31.1 \pm 3.2 \mathrm{~kg}$ (pre-test) $8 \pm 4.2 \mathrm{~kg}$ [post-test (Table 3)] explain the reduced body weight among elderly women in the control group.

The elderly women in the gardening intervention group maintained their lean mass, whereas those in control 
10 years (Jackson et al., 1995; Ogawa et al., 1992; Wilson and Tanaka, 2000). The results achieved with the low- to moderate-intensity gardening intervention in the present study indicated that such regular aerobic exercise could improve cardiopulmonary endurance in elderly women. Fifty percent of elderly older than 60 years experienced decreased function for agility and dynamic balance (Chevalier et al., 2008). This occurs as a result of either reduced muscle mass and bone mineral density or increased fat mass (Fraga et al., 2011; Guzmán et al., 2011); furthermore, the decreased mass increases the risk of falling (Rockwood et al., 2000) as well as making performance of daily living activities, such as walking, climbing stairs, or standing from a chair, more difficult (Motl and McAuley, 2010; de Noronha et al., 2011).

A significant improvement in hand dexterity was observed among elderly women in the gardening intervention group as indicated by the improvement from $136.9 \pm 69.3 \mathrm{~s}$ (pre-intervention) to $133.5 \pm 113.9 \mathrm{~s}$ [post-intervention, $P<0.05$ (Table $5)$ ]. The control group showed a decreased tendency for hand dexterity, although there was no significant difference between pre- and post-tests. Moreover, the intervention and control groups did not differ with respect to grip strength and pinch force (Table $5)$. In previous studies, horticultural activity programs were found to significantly improve hand dexterity in subjects with intellectual or developmental disabilities (Lee et al., 2010; Lee and Kim, 2007; Lee and Yoo, 2010; Moon and Yoo, 2009). Various horticultural activities are known to have kinematical properties that promote improved hand dexterity. For example, the subject's hand must approach and grasp horticultural materials and then transfer the materials to the target point (Lee et al., 2015). Accordingly, elderly women who participated in the gardening intervention repeatedly performed motions involving hand dexterity. Previous studies also showed improvements in grip strength and pinch force (Kim and Kim, 2008; Park et al., 2009; Yun and Kim, 2009). Park et al. (2009) reported that older gardeners exhibited significantly greater hand strength and pinch force, compared with older nongardeners. Indoor horticultural activity programs were

Table 4. Wilcoxon test comparisons of Senior Fitness Test of elderly women before and after a gardening intervention.

\begin{tabular}{|c|c|c|c|}
\hline \multirow[b]{2}{*}{ Sub tests } & & \multicolumn{2}{|c|}{ Group } \\
\hline & & $\frac{\text { Gardening }}{\text { Mean (SD) }}$ & $\begin{array}{c}\text { Control } \\
\text { Mean (SD) }\end{array}$ \\
\hline \multirow[t]{3}{*}{ Chair stand (n) } & Pre-test & $15.6(3.1)$ & $12.1(3.4)$ \\
\hline & Post-test & $16.5(3.2)$ & $12.8(3.8)$ \\
\hline & Significance & NS & NS \\
\hline \multirow[t]{3}{*}{ Arm curl (n) } & Pre-test & $19.9(3.6)$ & $16.7(3.2)$ \\
\hline & Post-test & $20.3(4.0)$ & $18.0(4.1)$ \\
\hline & Significance & NS & NS \\
\hline \multirow[t]{3}{*}{2 -min step (n) } & Pre-test & $79.4(31.4)$ & $53.4(21.6)$ \\
\hline & Post-test & $95.1(22.5)$ & $64.6(30.1)$ \\
\hline & Significance & * & NS \\
\hline \multirow[t]{3}{*}{ 8- $\mathrm{ft}^{\mathrm{z}}$ up-and-go (s) } & Pre-test & $7.0(1.6)$ & $7.2(1.4)$ \\
\hline & Post-test & $7.2(1.5)$ & $8.1(1.4)$ \\
\hline & Significance & NS & * \\
\hline \multirow[t]{3}{*}{ Chair sit-and-reach $(\mathrm{cm})^{\mathrm{z}}$} & Pre-test & $3.9(6.9)$ & $11.6(7.5)$ \\
\hline & Post-test & $8.0(9.2)$ & $13.3(8.5)$ \\
\hline & Significance & NS & NS \\
\hline \multirow[t]{3}{*}{ Back scratch $(\mathrm{cm})^{\mathrm{z}}$} & Pre-test & $-20.9(14.9)$ & $-17.2(11.5)$ \\
\hline & Post-test & $-22.2(12.2)$ & $-20.7(13.3)$ \\
\hline & Significance & NS & * \\
\hline
\end{tabular}

${ }^{\mathrm{z}} 1 \mathrm{~cm}=0.3937$ inch, $\mathrm{l} \mathrm{ft}=0.3048 \mathrm{~m}$.

Ns, *Nonsignificant or significant at $P<0.05$, respectively.

Table 5. Wilcoxon test comparisons of hand function ability of elderly women before and after a gardening intervention.

\begin{tabular}{|c|c|c|c|}
\hline \multirow[b]{2}{*}{ Hand function } & & \multicolumn{2}{|c|}{ Group } \\
\hline & & $\begin{array}{l}\text { Gardening } \\
\text { Mean (SD) } \\
\end{array}$ & $\begin{array}{c}\text { Control } \\
\text { Mean (SD) } \\
\end{array}$ \\
\hline \multirow[t]{3}{*}{ Grip force } & Pre-test & $17.6(4.8)$ & $16.9(3.1)$ \\
\hline & Post-test & $18.5(3.6)$ & $16.4(2.9)$ \\
\hline & Significance & NS & NS \\
\hline \multirow[t]{3}{*}{ Pinch force } & Pre-test & $6.7(0.9)$ & $6.2(1.0)$ \\
\hline & Post-test & $6.4(1.0)$ & $5.9(0.8)$ \\
\hline & Significance & NS & NS \\
\hline \multirow[t]{3}{*}{ Hand dexterity } & Pre-test & $136.9(69.3)$ & $125.4(43.0)$ \\
\hline & Post-test & $133.5(113.9)$ & $137.4(75.4)$ \\
\hline & Significance & * & NS \\
\hline
\end{tabular}

Ns, *Nonsignificant or significant at $P<0.05$, respectively.

found to increase grip strength in elderly subjects with stroke or dementia (Kim and Kim, 2008; Yun and Kim, 2009). In an observation of motions performed while gardening, Park and Shoemaker (2009) reported that gripping was the most frequently observed motion performed by older gardeners. Moreover, Park et al. (2013) measured muscle activation in the upper limb and hand muscles during 15 common horticultural activities and found that hand muscles such as the thenar eminence and hypothenar eminence were actively used during these activities.

PSYCHOLOGICAL HEALTH Assessments. According to the K-MMSE, elderly women in the 15-session gardening intervention experienced a significant improvement in cognitive function, with an increase in scores from $22.6 \pm 4.2$ to $23.6 \pm 2.8[P<$ 0.05 (Table 6)], although both scores remained in the mild cognitive impairment range (18-23) (Kang et al., 1997). A score in the range of 24-30 indicates no cognitive impairment (Kang et al., 1997). The pre- and postintervention scores of the control group did not significantly differ and remained in the mild cognitive impairment range. Similar to both groups in this study (Table 6), 10\% of individuals older than 65 years and $50 \%$ of those older than 85 years have mild cognitive impairment (Jorm and Jolley, 1998), 
showing that mild cognitive impairment is common in the elderly. Previously, a program that comprised 16 horticultural therapy sessions yielded improvements in cognitive function parameters, such as attention, memory, and visuospatial perception, in 10 male and female elderly individuals with dementia, and the brain metabolic rate was also shown to have increased via positron emission tomography (Cho, 2008). The positive results achieved in this and previous studies suggest that gardening activities provide opportunities for attention and orientation through caring for plants in the garden, which requires the consideration of weather conditions and plants' water and nutritive conditions (Bryant, 1991; Hass et al., 1998).

Notably, elderly women in the control group exhibited a significant increase in depression scores $[P<$ 0.05 (Table 6)], with symptoms progressing from normal before the intervention period to moderate depression symptom at the end of the study. Meanwhile, the depression scores of elderly women in the gardening intervention group did not change during this period (Table 6), and the pretest depression scores indicated a normal condition. In the elderly, depression can lead to a loss of cognitive function, decreased life satisfaction, and suicide (Almeida et al., 2006).

Table 6. Wilcoxon test comparisons of cognitive ability, depression, and sociality of elderly women before and after a gardening intervention.

\begin{tabular}{llcc}
\hline & & \multicolumn{2}{c}{ Group } \\
\cline { 3 - 4 } Variable & & Gardening & Control \\
\hline $\begin{array}{c}\text { Mini mental state examination } \\
(0-30 \text { scale) }(\text { K-MMSE) }\end{array}$ & Pre-test & $22.6(4.2)$ & $22.1(3.7)$ \\
& Post-test & $23.6(2.8)$ & $21.8(3.5)$ \\
Geriatric depression scale & Significance & $*$ & Mean (sD) \\
$(0-15$ scale) $($ GDSSF-K) & Pre-test & $4.9(2.8)$ & $3.3(2.5)$ \\
& Post-test & $4.7(2.7)$ & $5.1(2.9)$ \\
Sociality & Significance & Ns & $* * *$ \\
& Pre-test & $80.0(9.5)$ & $71.4(7.8)$ \\
& Post-test & $83.0(5.1)$ & $73.4(7.7)$ \\
& Significance & NS & NS \\
\hline
\end{tabular}

${ }^{2} \mathrm{~K}-\mathrm{MMSE}$ : $0-17$ = severe cognitive impairment, $18-23=$ mild cognitive impairment, $24-30=$ no cognitive impairment (Kang et al., 1997).

${ }^{y}$ GDSSF-K: $<5=$ normal, $6-9=$ moderate, $>10=$ severe $(\mathrm{Ki}, 1996)$.

Ns, ${ }^{*},{ }^{* *}$ Nonsignificant or significant at $P<0.05$ and $P<0.001$, respectively.

Table 7. Wilcoxon test comparisons of physical activity level of elderly women before and after a gardening intervention.

\begin{tabular}{|c|c|c|c|}
\hline \multirow[b]{2}{*}{$\begin{array}{l}\text { Physical activity } \\
\text { (MET-min/week) }\end{array}$} & & \multicolumn{2}{|c|}{ Group } \\
\hline & & $\begin{array}{l}\text { Gardening } \\
\text { Mean (sD) }\end{array}$ & $\begin{array}{c}\text { Control } \\
\text { Mean (SD) }\end{array}$ \\
\hline \multirow[t]{3}{*}{ Walkingy } & Pre-test & $1,313.1(855.4)$ & $745.8(656.4)$ \\
\hline & Post-test & $1,507.6(1,100.6)$ & $483.6(546.0)$ \\
\hline & Significance & NS & NS \\
\hline \multirow[t]{3}{*}{ Moderate $^{y}$} & Pre-test & $709.5(709.8)$ & $360(802.0)$ \\
\hline & Post-test & $685.3(466.3)$ & $221.5(316.9)$ \\
\hline & Significance & NS & NS \\
\hline \multirow[t]{3}{*}{ Vigorous $^{y}$} & Pre-test & $134.7(515.1)$ & $166.2(431.4)$ \\
\hline & Post-test & $976.9(1,279.0)$ & $443.0(1,597.5)$ \\
\hline & Significance & * & NS \\
\hline \multirow[t]{3}{*}{ Total $^{y}$} & Pre-test & $2,157.3(973.3)$ & $1,237.8(1,243.8)$ \\
\hline & Post-test & $3,169.7(1,832.5)$ & $1,148.2(1,557.5)$ \\
\hline & Significance & NS & NS \\
\hline
\end{tabular}

${ }^{\mathrm{z}}$ Self-reported physical activity measured in metabolic equivalent of task (MET)-min. A MET-min is computed by multiplying the MET score by the minutes performed (IPAQ Research Committee, 2005).

${ }^{y}$ Walking MET-min/week $=3.3 \times$ walking minutes $\times$ walking days, moderate MET-min $/$ week $=4.0 \times$ moderateintensity activity minutes $\times$ moderate days, vigorous MET- $\mathrm{min} /$ week $=8.0 \times$ vigorous-intensity activity minutes $\times$ vigorous-intensity days. A combined total physical activity MET-min/week can be computed as the sum of walking + moderate + vigorous MET-min/week scores (IPAQ Research Committee, 2005).

Ns, *Nonsignificant or significant at $P<0.05$, respectively.
Joshi et al. (2016) reported that elderly individuals who participate in physical activity have low levels of depression symptoms and that gardening acted to prevent depression in this population. A 12-session gardening program was previously found to improve depression symptoms and life satisfaction in an elderly population (Kim et al., 2013). The positive psychological effects of gardening can be attributed to the increased production of alpha waves in the brain as a result of the restful sensations from green plants, as determined in a previous study (Son et al., 1999).

Neither study group experienced a difference in sociality following the intervention period (Table 6). Sociality is a crucial factor associated with life satisfaction and wellbeing in later life (Carstensen, 1995; Nezlek et al., 2002). Although elderly women in this study did not experience improved sociality, previous studies have reported positive effects of gardening interventions on sociality. For example, Tse (2010) reported significantly improved social relationships among 26 elderly nursing home residents after participating in an 8-session gardening program. Moreover, 12 independently living elderly subjects who participated in a gardening intervention reported improved social support (Oh and Yoo, 2010). An expanded gardening intervention period or customized gardening program by considering the subject characteristics could be applied to improve sociality among elderly participants.

In this study, elderly women who participated in the gardening intervention experienced a significant increase in the amount of daily physical activity (Table 7 ). In particular, the amount of time spent on vigorous physical activities increased from $134.7 \pm 515.1$ MET-min/week (preintervention) to $976.9 \pm 1290.0 \mathrm{MET}$ $\mathrm{min} /$ week (post-intervention, $P=$ $0.02)$. In contrast, elderly women in the control group exhibited a nonsignificant tendency toward a reduced amount of daily physical activity (Table 7). Compared with indoor activities, outdoor activities such as gardening might help to motivate individuals to participate in exercise interventions and remain physically active (Department of Health, 2004; Park et al., 2008a, 2009). Seasonal variations and plant growth cycles also contribute to the 
motivation to participate in a gardening exercise intervention (Park et al., $2008 \mathrm{~b}$ ) because of the need to continuously care for plants in the garden and an interest in the plants' growth cycles (Lekies and Sheavly, 2007; Park et al., 2008b).

SATISFACTION WITH THE GARDENING INTERVENTION. Overall, most elderly women in the gardening intervention group reported being very satisfied $(87.5 \%, 21$ respondents $)$, satisfied $(8.3 \%, 2$ respondents), or moderately satisfied $(4.2 \%, 1$ respondent) with the gardening intervention. Participants were very satisfied $(70.8 \%, 17$ respondents) and satisfied $(25 \%, 6$ respondents) with the average duration of $50 \mathrm{~min}$ per session. Similarly, participants were very satisfied $(91.7 \%, 22$ respondents $)$ and satisfied $(8.3 \%, 2$ respondents) with the session frequency of twice per week. Regarding preferences for gardening activities, planting transplants $(54.7 \%, 1.6$ points) was the most preferred activity, followed by flower arrangement $(48 \%, 1.4$ points), harvesting $(40 \%, 1.2$ points $)$, garden parties $(30.7 \%, 0.9$ points $)$, and making eco-friendly fertilizers $(21.3 \%, 0.6$ points). Regarding the benefits of gardening, elderly women who participated in the gardening intervention subjectively reported they enjoyed group activity $(91.7 \%, 22$ respondents), psychological relaxation $(87.5 \%, 21$ respondents), the fun of raising plants (83.3\%, 20 respondents), and leisure time activity $(70.8 \%, 17$ respondents $)$. Moreover, all participants $(100 \%, 24$ respondents) reported that they wished to continue participating in the gardening intervention and would recommend it to other elderly people.

In conclusion, the gardening intervention, as a low- to moderateintensity physical activity, improved the physical and psychological health conditions of elderly women who participated in this study at a senior community center. The elderly women in the 15-session gardening intervention significantly reduced waist circumference and improved aerobic endurance, hand dexterity, cognitive function, and their amount of daily physical activity. On the other hand, the elderly women in the control group experienced age-related reduced physical and psychological health conditions for lean mass, agility, and depression. Moreover, satisfaction with the gardening intervention as a leisure time physical activity for health conditions of elderly women was very high. Future studies should include a larger population and longer gardening intervention period to determine the effects of the intervention and improve the health conditions of the elderly participants.

\section{Literature cited}

Aaron, S.D., D. Fergusson, R. Dent, Y. Chen, K.L. Vandemheen, and R.E. Dales. 2004. Effect of weight reduction on respiratory function and airway reactivity in obese women. CHEST J. 125:2046-2052.

Ainsworth, B.E., W.L. Haskell, M.C. Whitt, M.L. Irwin, A.M. Swartz, S.J. Strath, W.L. O’Brien, D.R. Bassett, Jr., K.H. Schmitz, P.O. Emplaincourt, D.R. Jacobs, Jr., and A.S. Leon. 2000. Compendium of physical activities: An update of activity codes and MET intensities. Med. Sci. Sports Exerc. 32:S498-S504.

Almeida, O.P., P. Norman, G. Hankey, K. Jamrozik, and L. Flicker. 2006. Successful mental health aging: Results from a longitudinal study of older Australian men. Amer. J. Geriatr. Psychiatry 14:27-35.

Ashe, M.C., W.C. Miller, J.J. Eng, and L. Noreau. 2009. Older adults, chronic disease and leisure-time physical activity. Gerontology 55:64-72.

Bae, D.J. 2009. The effect of involvement, physical ability, sociality and life satisfaction of old's leisure activity characteristics. PhD Diss., Wonkwang Univ., Iksan, Korea.

Barnsley, R.H. and S. Rabinovich. 1970. Handedness: Proficiency versus stated preference. Percept. Mot. Skills 30:343362 .

Bassey, E.J. and S.J. Ramsdale. 1995. Weight-bearing exercise and ground reaction forces: A 12-month randomized controlled trial of effects on bone mineral density in healthy postmenopausal women. Bone 16:469-476.

Baumgartner, R.N., K.M. Koehler, D. Gallagher, L. Romero, S.B. Heymsfield, R. R. Ross, P.J. Garry, and R.D. Lindeman. 1998. Epidemiology of sarcopenia among the elderly in New Mexico. Amer. J. Epidemiol. 147:755-763.

Brandtstädter, J. and W. Greve. 1994. The aging self: Stabilizing and protective processes. Dev. Rev. 14:52-80.

Brown, M., D.R. Sinacore, A.A. Ehsani, E.F. Binder, J.O. Holloszy, and W.K. Kohrt. 2000. Low-intensity exercise as a modifier of physical frailty in older adults. Arch. Phys. Med. Rehabil. 81:960-965.

Bryant, W. 1991. Creative group work with confused elderly people: A development of sensory integration therapy. Brit. J. Occup. Ther. 54:187-192.

Buford, T.W., S.D. Anton, A.R. Judge, E. Marzetti, S.E. Wohlgemuth, C.S. Carter, C. Leeuwenburgh, M. Pahor, and T.M. Manini. 2010. Models of accelerated sarcopenia: Critical pieces for solving the puzzle of age-related muscle atrophy. Ageing Res. Rev. 9:369-383.

Buman, M.P., E.B. Hekler, W.L. Haskell, L. Pruitt, T.L. Conway, K.L. Cain, J.F. Sallis, B.E. Saelens, L.D. Frank, and A.C. King. 2010. Objective light-intensity physical activity associations with rated health in older adults. Amer. J. Epidemiol. 172:1155-1165.

Burns, J.M., D.K. Johnson, A. Watts, R.H. Swerdlow, and W.M. Brooks. 2010. Reduced lean mass in early Alzheimer disease and its association with brain atrophy. Arch. Neurol. 67:428-433.

Carstensen, L.L. 1995. Evidence for a lifespan theory of socioemotional selectivity. Curr. Dir. Psychol. Sci. 4:151-156.

Chevalier, S., F. Saoud, K. Gray-Donald, and J.A. Morais. 2008. The physical functional capacity of frail elderly persons undergoing ambulatory rehabilitation is related to their nutritional status. J. Nutr. Health Aging 12:721-726.

Cho, M.K. 2008. Horticultural therapy as non-pharmacological treatment for the improvement of cognitive function and BPSD in dementia. PhD Diss., Konkuk Univ., Seoul, South Korea.

de Noronha, D.F., R.G. de Souza, T.S. Giani, S. Bacellar, T. Escobar, M. Stoutenberg, and E.H. Dantas. 2011. Correlation between static balance and functional autonomy in elderly women. Arch. Gerontol. Geriatr. 52:111-114.

de Rezende, L.F.M., J.P. Rey-López, V.K.R. Matsudo, and O. do Carmo Luiz. 2014. Sedentary behavior and health outcomes among older adults: A systematic review. BMC Public Health 14:333.

Department of Health. 2004. At least 5 a week: Physical activity and health outcomes: A review of the chief medical officer. Dept. Health, London, UK.

DiPietro, L. 2001. Physical activity in aging changes in patterns and their relationship to health and function. J. Gerontol. A Biol. Sci. Med. Sci. 56(Suppl. 2):13-22.

Driscoll, I., D.A. Hamilton, H. Petropoulos, R.A. Yeo, W.M. Brooks, R.N. Baumgartner, and R.J. Sutherland. 2003. The aging hippocampus: Cognitive, biochemical and structural findings. Cereb. Cortex 13:1344-1351.

Dunstan, D.W., B. Howard, G.N. Healy, and N. Owen. 2012. Too much 
sitting - A health hazard. Diabetes Res. Clin. Pract. 97:368-376.

Fiske, A., J.L. Wetherell, and M. Gatz. 2009. Depression in older adults. Annu. Rev. Clin. Psychol. 5:363-389.

Fleishman, E.A. 1972. Structure and measurement of psychomotor abilities, p. 78-196. In: S.N. Singer (ed.). The psychomotor domain. Lea Febiger, Philadelphia, PA.

Ford, E.S., A.H. Mokdad, and W.H. Giles. 2003. Trends in waist circumference among U.S. adults. Obes. Res. 11: 1223-1231.

Fraga, M.J., S.A. Cader, M.A. Ferreira, T.S. Giani, and E.H. Dantas. 2011. Aerobic resistance, functional autonomy and quality of life (QoL) of elderly women impacted by a recreation and walking program. Arch. Gerontol. Geriatr. 52:40-43.

Guzmán, R.A., H.A. Salazar, A. Cea, H.P. Melián, B. Cordier, and R.A. Silvestre. 2011. Correlation between the scores of "Timed up and go" test and registered joint moments of lower limb during the sit-to-stand transfer in elderly with antecedents of frequent falls. Intl. J. Morphol. 29:521-525.

Hass, K., S.P. Simson, and N.C. Stevenson. 1998. Older persons and horticultural therapy practice, p. 231-252. In: S.P. Simson and M.C. Straus (eds.). Horticulture as therapy: Principles and practice. Haworth Press, New York, NY.

Huxley, R., S. Mendis, E. Zheleznyakov, S. Reddy, and J. Chan. 2010. Body mass index, waist circumference and waist: Hip ratio as predictors of cardiovascular risk: A review of the literature. Eur. J. Clin. Nutr. 64:16-22.

IPAQ Research Committee. 2005. Guidelines for data processing and analysis of the International Physical Activity Questionnaire (IPAQ)-short and long forms. 20 Mar. 2016. <http://www.ipaq.ki.se>.

Jackson, A.S., E.F. Beard, L.T. Wier, R.M. Ross, J.E. Stuleville, and S.W. Blair. 1995. Changes in aerobic power of men ages 25-70 yr. Med. Sci. Sports Exerc. 27:113-120.

Janssen, I., S.B. Heymsfield, and R. Ross. 2002. Low relative skeletal muscle mass (sarcopenia) in older persons is associated with functional impairment and physical disability. J. Amer. Geriatr. Soc. 50:889-896.

Jorm, A.F. and D. Jolley. 1998. The incidence of dementia: A meta-analysis. Neurology 51:728-733.

Joshi, S., S.J. Mooney, G.J. Kennedy, E.O. Benjamin, D. Ompad, A.G. Rundle, J.R. Beard, and M. Cerdá. 2016. Beyond METs: Types of physical activity and depression among older adults. Age Ageing 45:103-109.

Kang, Y.W., D. Na, and S.H. Hahn. 1997. A validity study on the Korean mini-mental state examination (K-MMSE) in dementia patients. J. Korean Neurol. Assoc. 15:300-308.

Kelley, G.A., K.S. Kelley, and W.M. Kohrt. 2013. Exercise and bone mineral density in men: A meta-analysis of randomized controlled trials. Bone 53:103-111.

Ki, B.S. 1996. A preliminary study for the standardization of Geriatric Depression Scale Short Form-Korea version. J. Korean Neuropsychiatr. Assoc. 35:298-302.

Kim, H.W., S. Lee, and S.M. Lee. 2013. Effects of horticultural activities leisure program on mental health and life-satisfaction of the rural elderly. J. Korean Soc. People Plants Environ. 16:125-132.

Kim, H.Y. and D.Y. Kim. 2008. Effects of horticultural therapy on the hand functions and cognitive abilities in elders with severe brain lesions. J. Korean Soc. People Plants Environ. 11:99-103.

Korean Meteorological Administration. 2015. Past Material, Korean Climatological Data. K MA, Seoul, South Korea. 10 Dec. 2015. <http://www.kma.go.kr/ weather/climate/past_cal.jsp >.

Lahti-Koski, M., K. Harald, S. Mannisto, T. Laatikainen, and P. Jousilahti. 2007. Fifteenyear changes in body mass index and waist circumference in Finnish adults. Eur. J. Cardiovasc. Prev. Rehabil. 14:398-404.

Lee, A.Y., S.A. Park, J.J. Kim, J.M. So, and K.C. Son. 2015. Biomechanics analysis of horticulture activity motions for health. Korean J. Hort. Sci. Technol. 33 (Suppl. II):60 (abstr.).

Lee, M.H. and Y.K. Yoo. 2010. Effects of horticultural therapy on the self-esteem, psychosocial behavior, emotional behavior and hand function in disabled person. J. Korean Soc. People Plants Environ. 13:9-16

Lee, M.J. and H.Y. Kim. 2007. Effect of a horticultural therapy program on vocational skills of the mentally disabled. J. Korean Soc. People Plants Environ. 10:26-33.

Lee, M.J., H.Y. Kim, and J.Y. Cho. 2010. Effect of horticultural therapy program on hand function and emotional behavior of the intellectual challenged people. J. Korean Soc. People Plants Environ. 13:1-6.

Lee, S.Y., H.S. Park, D.J. Kim, J.H. Han, S.M. Kim, G.J. Cho, D.Y. Kim, H.S. Kwon, S.R. Kim, C.B. Lee, S.J. Oh, C.Y. Park, and H.J. Yoo. 2007. Appropriate waist circumference cutoff points for central obesity in Korean adults. Diabetes Res. Clin. Pract. 75:72-80.
Lekies, K.S. and M.E. Sheavly. 2007. Fostering children's interests in gardening. Appl. Environ. Educ. Commun. 6:67-75.

Libardi, C.A., G.V. De Souza, C.R. Cavaglieri, V.A. Madruga, and M.P. Chacon-Mikahil. 2012. Effect of resistance, endurance, and concurrent training on TNF-a, IL-6, and CRP. Med. Sci. Sports Exerc. 44:50-56.

Lovell, S.T. 2010. Multifunctional urban agriculture for sustainable land use planning in the United States. Sustainability 2:2499-2522.

McClintock, N. 2010. Why farm the city? Theorizing urban agriculture through a lens of metabolic rift. Camb. J. Regions Econ. Soc. 3:191-207.

Moon, J.R. and Y.K. Yoo. 2009. Effects of horticultural therapy on the psychosocial behavior, emotional behavior and hand dexterity in mentally retarded middleschool boys. J. Korean Soc. People Plants Environ. 12:9-15.

Motl, R.W. and E. McAuley. 2010. Physical activity, disability, and quality of life in older adults. Phys. Med. Rehabil. Clin. N. Amer. 21:299-308.

Mougeot, L.J.A. 2006. Growing better cities: Urban agriculture for sustainable development. Intl. Dev. Res. Ctr., Ottawa, ON, Canada.

Nelson, M.E., W.J. Rejeski, S.N. Blair, P.W. Duncan, J.O. Judge, A.C. King, C.A. Macera, and C. Castaneda-Sceppa. 2007. Physical activity and public health in older adults: Recommendation from the American College of Sports Medicine and the American Heart Association. Circulation 116:1094-1105.

Nezlek, J.B., D.S. Richardson, L.R. Green, and E.C. Schatten-Jones. 2002. Psychological well-being and day-to-day social interaction among older adults. Pers. Relatsh. 9:57-71.

Ogawa, T.R., R. Spina, W.H. Martin, W.M. Kohrt, K.B. Schechtman, J.O. Holloszy, and A.A. Ehsani. 1992. Effects of aging, sex and physical training on cardiovascular responses to exercise. Circulation 86:494-503.

Oh, H.J. and Y.K. Yoo. 2010. Effects of horticultural activity on the social support and self-esteem in solitary old adult. J. Korean Soc. People Plants Environ. 13:45-52.

Park, S.A. and C.A. Shoemaker. 2009. Observing body position of older adults while gardening for health benefits and risks. Act. Adaptation Aging 33:31-38.

Park, S.A., A.Y. Lee, H.S. Lee, K.W. Lee, and K.C. Son. 2015. A comparison of exercise intensity between two horticultural and four common physical activities 
among male adults in their 20s. Korean J. Hort. Sci. Technol. 33:133-142.

Park, S.A., A.Y. Lee, J.J. Kim, K.S. Lee, J.M. So, and K.C. Son. 2014b. Electromyographic analysis of upper and lower limb muscles during gardening tasks. Korean J. Hort. Sci. Technol. 32:710-720.

Park, S.A., C.A. Shoemaker, and M.D. Haub. 2008a. A preliminary investigation on exercise intensities of gardening tasks in older adults. Percept. Mot. Skills 107: 974-980.

Park, S.A., C.A. Shoemaker, and M.D. Haub. 2008b. Can older gardeners meet the physical activity recommendation through gardening? Hort Technology 18:639-643.

Park, S.A., C.A. Shoemaker, and M.D. Haub. 2009. Physical and psychological health conditions of older adults classified as gardeners or nongardeners. HortScience 44:206-210.

Park, S.A., J.Y. Lee, K.S. Lee, and K.C. Son. 2014a. Metabolic costs of daily activities in community-dwelling older adults. Intl. J. Gerontol. 8:228-229.

Park, S.A., K.S. Lee, and K.C. Son. 2011. Determining exercise intensities of gardening tasks as a physical activity using metabolic equivalents in older adults. HortScience 46:1706-1710.

Park, S.A., K.S. Lee, K.C. Son, and C.A. Shoemaker. 2012. Metabolic cost of horticulture activities in older adults. J. Jpn. Soc. Hort. Sci. 81:295-299.

Park, S.A., S.R. Oh, K.S. Lee, and K.C. Son. 2013. Electromyographic analysis of upper limb and hand muscles during horticultural activity motions. HortTechnology 23:51-56.

Pate, R.R., M. Pratt, S.N. Blair, W.L. Haskell, C.A. Macera, C. Bouchard, D. Buchner, W. Ettinger, G.W. Heath, A.C. King, A. Kriska, A.S. Leon, B.H. Marcus, J. Morris, R.S. Paffenbarger, Jr., K. Patrick, M.L. Pollock, J.M. Rippe, J. Sallis, and J.H. Wilmore. 1995. Physical activity and public health: A recommendation from the Centers for Disease Control and Prevention and the American College of Sports Medicine. J. Amer. Medical Assn. 273:402-407.

Rikli, R.E. and C.J. Jones. 1999a. Functional fitness normative scores for community- residing older adults, ages 60-94. J. Aging Phys. Act. 7:162-181.

Rikli, R.E. and C.J. Jones. 1999b. Development and validation of a functional fitness test for community-residing older adults. J. Aging Phys. Act. 7:129-161.

Rikli, R.E. and C.J. Jones. 2001. Senior fitness test. Human Kinetics, Champaign, IL.

Rikli, R.E. and C.J. Jones. 2013. Senior fitness test manual. Human Kinetics, Champaign, IL.

Rockwood, K., E. Awalt, D. Carver, and C. Macknightm. 2000. Feasibility and measurement properties of the functional reach and the timed up and go tests in the Canadian Study of Health and Aging. J. Gerontol. A Biol. Sci. Med. Sci. 55:70-73.

Rowinski, R., A. Dabrowski, and T. Kostka. 2015. Gardening as the dominant leisure time physical activity (LTPA) of older adults from a post-communist country. The results of the populationbased PolSenior Project from Poland. Arch. Gerontol. Geriatr. 60:486-491.

Seok, M.R. 2005. The influence of physical ability and sociability of the aged on the participation and satisfaction of leisure. PhD Diss., Keimyung Univ., Daegu, Korea.

Son, K.C., J.S. Lee, and J.E. Song. 1999. Effect of visual recognition of Ficus benjamina and its photograph on changes of human brain electroencephalography and brain blood flow. Hort. Environ. Biotechnol. 40:134-138.

Song, S.H. 2000. A study of the relationships between the teachers' sociability and their perspectives. MS Diss., Cheju Natl. Univ., Jeju, Korea.

Stewart, K.J. 2005. Physical activity and aging. Ann. N. Y. Acad. Sci. 1055:193-206.

Tse, M.M.Y. 2010. Therapeutic effects of an indoor gardening programme for older people living in nursing homes. J. Clin. Nurs. 19:949-958.

Turner, L.W., M.A. Bass, L. Ting, and B. Brown. 2002. Influence of yard work and weight training on bone mineral density among older U.S. women. J. Women Aging 14:139-148.

van Leeuwen, E., P. Nijkamp, and T.D. Vaz. 2010. The multifunctional use of urban greenspace. Intl. J. Agr. Sustain. 8:20-25.

Weir, P. 2010. Physical activity: What role does it play in achieving successful aging? p. 159-172. In: J. Baker, S. Horton, and P. Weir (eds.). The masters athlete: Understanding the role of sport and exercise in optimizing aging. Routledge, London, UK.

Wilson, T.M. and H. Tanaka. 2000. Metaanalysis of the age-associated decline in maximal aerobic capacity in men: Relation to training status. Amer. J. Physiol. Heart Circ. Physiol. 278:H829-H834.

World Health Organization. 2011. Waist circumference and waist-hip ratio: Report of a WHO expert consultation, Geneva, 811 Dec. 2008. WHO, Geneva, Switzerland.

Yesavage, J.A. and J.I. Sheikh. 1986. 9/ Geriatric Depression Scale (GDS) recent evidence and development of a shorter violence. Clin. Gerontol. 5:165-173.

Yun, S.Y. and H.Y. Kim. 2009. Effect of the horticultural therapy on hand function of demented elders. Korean J. Hort. Sci. Technol. 27:673-677. 